\title{
Enhancing Communication Skills of Counselor Teachers Based on Neuro-Linguistic Programming Theory
}

\author{
Zhang Xue, Lv Shanhui, Li Heti, Sun Hui, Zhang Jingxuan, Chen Yan \& Guo Yu \\ Hebei United University, Tangshan, China
}

Liu Yunqiu \& Hu Qingxi

China University of Petroleum, Beijing, China

\begin{abstract}
As the backbone for moral education in university, counselors play the role of teacher and friend. And communication with college students is an important part for the work. For better communicate with college students, this article investigates the current situation of communication between counselor teachers and students, analyses the influencing factors and finally proposes suggestions that the counselors should enhance communication skills, focus on the student's consciousness and subconsciousness, and broaden communication channels based on Neuro-Linguistic Programming theory and method.
\end{abstract}

KEYWORD: Neuro-Linguistic Programming Theory; Counselor Teachers; Communication Skills

\section{NEURO-LINGUISTIC PROGRAMMING THEORY}

\subsection{NLP Concepts}

Neuro-Linguistic Programming, short for NLP, is a science to research on how the brain work and coordinate for more successful and happier life according to the book of Reconstrucing Minds, Li zhongying wrote in 2006. Neuro means that the nerve system which are linked by brain and body controls sensitive and functional organs to maintain connection with the outside world. Linguistic means that the language models and grammar rules connected by brain and body display our thinking mode, belief and state of mind through posture, gesture, behavior and habits. Programming means that it is scientific programs that we can use to point out that our thought, sense and behavior are just regular modes, and can be improved by updating software.

\subsection{NLP fundamental assumptions}

NLP fundamental assumptions are the key that we use to deal with problems. There are 12 assumptions as below:

No two persons are the same; one person cannot change another person; usefulness is more important; the map is not territory; the meaning of communication is the response one gets; repeating the same behavior will repeat the same result; there are at least 3 solutions to every situation; every one chooses the best behaviors at the moment; every one already possesses all the resources needed; in any system, the most flexible person has the control; there is no failure, only feedback; intentions and emotions are never wrong, only the behavior has not been effective.

\subsection{Impact of $N L P$}

NLP has positive impact on life, because it selects thought, language and behavior that coordinate with brain to help us to improve bringing more relaxation, satisfaction, success and delight. In the interaction, NLP helps us to master how to get what a person thinks and cooperate with him effectively. From the words, NLP helps us to precept what kind of expression, intonation and body language can make others easily accept.

\section{PRACTICAL SIGNIFICANCE FOR COUNSELOR COMMUNICATION}

\subsection{Improve student's sociability}

College students have strong sense of need to develop friendship, but their social skills are not good as we expected. Therefore, it is advisable for the counselor to offer them concern, love and help for every individual student. On one hand, students can learn from the counselor on how to get along well with other people. On the other hand, they can get from the counselor the feedback, which helps evaluate themselves comprehensively, accept the difference from others and better integrate to a team. 


\subsection{Develop healthy personality for students}

Most college students are lonely and doleful when they are faced with difficulty in daily life. Therefore, it is suggested that the counselor find out the troubling problem, guide them to behave appropriately, help them to think the problem with positive attitude and figure it out with wisdom. It is what the counselor instructs and behaves during the communication that set an example of good characters for the students. These good characters include kindness, sincere, warm-hearted, easy-going and so on.

\subsection{Strengthen the emotional connection with students}

A psychological distance exists in the student's mind because the counselor lies in the managing position, and some students are afraid to contact the counselor. An open conversation between the the counselor and students can make them identify with each other and enhance the trust and understanding. And the counselor is concerned with the student's psychological expectation and makes it as his own aim, and the student do it in the same way, and that can deepen the emotional relationship between the counselor and the student.

\section{COMMUNICATION PROBLEMS}

\subsection{The counselor}

In some universities, there lacks in personnel allocation for counselors. The university ought to equip counselors at at least 1:200 to students according to China State Education Ministry. Actually, a counselor is responsible for 300 or more students, and he has no redundant time and effort to have deep communication with every student. According to a survey, a part of counselors do not have strong work enthusiasm, they believe this work is heavy with low pay, and they want to be a fulltime teacher in the near future. Some counselors do not care for communication work, for they think it is not related to performance assessment and appraisal.

The counselors lack in communication skills. Most counselors cannot master the cognitive, thinking, and psychological mechanism of college students, for the reason that they have not attended the training for communication skills. A small part of counselors even have communication obstacles with their colleagues or leaders. These counselors cannot listen attentively to students, use different tactics to different students, praise or criticize students in appropriate circumstances, as a result, the moral education cannot be effective as so-called reaching the brain, the ear and the mind of college students.
The counselors are lack of personality charm which affects the student's intention to have a dialogue. Those counselors who are enthusiastic, easy-going, humorous are often attracted to students to interact with. In contrast, students are not intended to communicate with those counselors who are serious, indifferent and commanding. Some counselors work in simple and rough method, with more orders than negotiation, more power than equality, more criticism than concern, which makes the students far away from them.

\subsection{The students}

The students that the counselor chooses to communicate are restricted to the excellent or the poor in academics. However, the general students who have average performance are often neglected. According to a survey, more than half of the students have official talks at most twice every semester for each student. And 35\% students have no opportunity to contact with counselors during the whole semester. And the main reason to contact counselors is just to hand in papers for most of the times, but seldom for consulting psychological confusion.

A large part of college students are not mature in mind. Some students are obscure in ideal and belief, so they hardly confirm to the counselor's instructions. Some students regularly take themselves as the core with strong self-esteem and rebellious attitude. Some students are stubborn with stereotypes, which is formed in their early growing period. Some students have conflicts in inner values for they are influenced by many social values some of which are not good. Some students often fluctuate emotionally, and have many psychological confusions. All of these weaken the communication effect.

\subsection{The communication process}

The information are not equally passed to the counselor and the student. It is a fact that the counselor occupies the higher positon with more voice than the student. So it is obvious that the counselor has information advantage. Sometimes, the counselor deprives the student's discourse to speech by instilling unconsciously. Besides, When the counselor communicates with the student, information that they transmit can be lessened or changed from one student to another, which also results in communication barriers.

Emotional communication are often neglected. Sometimes, the counselor is not familiar with the student, or not deep into student's mind to conduct a heart-to-heart dialogue, thus they cannot establish the real trust or understanding among students. Some counselors have not fully shown respect to 
students in the dialogue, as they do not take the student's need into consideration, with the result of psychological conflict or distance.

\subsection{The communication media and environment}

The way to communicate is too single. Most counselors mainly depend on face-to-face communication, but at the other extreme, a few counselors only use modern technology instead of the talk face to face. Actually, they should make full use of advanced tools, such as QQ, MSN, microblog, micro-letter, social network, and also stick to the traditional methods like class meeting, dorm visit and face-to-face tutoring.

The talk time and place is too limited. The communication usually happens in the counselor's office during the work hour, but not in the dorm, playground, or other outside places after work. In most cases, the conversation is completed in less than 10 minutes. Most students are too serious to say their real idea, while they just listen to the counselor with no response or just reluctant echo.

\section{STRENGTHENING COMMUNICATION SKILLS AND ART BASED ON NLP}

\subsection{Enhance communication skills}

NLP Theory said, the meaning of communication is the response one gets. Similarly, the meaning of commnication between the counselor and the student is decided by the student's response. There are many methods and skills. As to interaction, the counselor should repeat the important words the student said, indicating he cares for the student's feeling. He should response to the student with sharing his own experience, feeling and real idea, showing that he accepts the student's thoughts. It is an effective way that the counselor uses a story of another person to illustrate what he wants the student to understand. Another method is that the counselor firstly agrees with the student, and then guides him to think in the counselor's or other people's perspective. As to expression, we advise that the counselor use simple, lively words which meets the students' sensational, psychological and social demand. In addition, the counselor can use body language as gestures, eye contact, nodding, facial expressing to extend friendship to the students.

\subsection{Focus on consciousness and subconsciousness}

It is indispensable to care for conscious and subconscious mind. The thinking, emotion and behaviour are decided by what the student has identified, that is consciousness. And what influences his thinking mostly comes from his subconsciousness. Base on NLP theory, every one has his own belief, value and rules, short for BVR. If you hope that he accepts your point of view, you should seek from his BVR the better solution that brings him more benefits he longs for than his original decision. Then you guide him to realize and follow it, and he will change himself to the new solution that you propose. The counselor ought to take himself to the position for the students, think in their BVR, receive their real ideas, but not instill his own BVR to them. After understanding the inner world of the student, the counselor can explore the same or similar BVR to share with the student. And that can evoke the student on intimate terms with the counselor.

Listening is a bridge that brings the counselor and the student together through heart-to-heart dialogue. Firstly, The counselor gets what the student want to convey, what his personal character is, and what results in the psychological problem. Then, the counselor transits what he gets from seeing and hearing, to the students at proper time and place, and help students to find out the problem and solve it themselves.

\subsection{Broaden communication channels}

There are many ways to communicate with students, for example, the counselor can take part in activities with students to deepen teacher-student relationship. Moreover, it is advisable to use modern network technology, such as QQ, MSN, micro-blog, microletter, to expand contacting span with students. On one hand, from web logs and photos, the counselor can master what the students are thinking, doing and planning, to find out the potential danger or risk among students in time. On the other hand, through chatting online, the counselor can easily go to the student's inner world, show the concern, win back the trust, and reduce the psychological defense from students.

\section{CONCLUSIONS}

Communication is a common process during which a person can transit his thought, emotion and information to others by verbal and nonverbal symbols. And the same is to the counselor and his students. Communication between counselor and the student is the process when they get to know, understand and learn from each other and gradually reach a consensus through heart-to-heart conversation. This article applies NLP theory in teacher-student communication practice, analyzes the communication status quo and problems and propose suggestions on how to improve the counselor's communication skills for better work in the future. That is to enhance communication skills, focus on the student's consciousness and 
subconsciousness, and broaden communication channels. This research is supported by the program of Education Department of Hebei Province, China, No.SZ141100, with the name of enhancing influencing strategy for counselor teachers in university based on NLP theory.

\section{REFERENCES}

[1] Li, zhongying. 2006. Reconstructing minds. Beijing: World Book Company. 